\title{
Ectopic Dendritogenesis and Associated Synapse Formation in Swainsonine-Induced Neuronal Storage Disease
}

\author{
S. U. Walkley, D. A. Siegel, and S. Wurzelmann \\ Department of Neuroscience, Rose F. Kennedy Center for Research in Mental Retardation and Human Development, \\ Albert Einstein College of Medicine, Bronx, New York 10461
}

Ectopic dendrite growth and new synapse formation are known to occur on select kinds of neurons in a wide variety of neuronal storage diseases. As these changes in connectivity occur just proximal to the axonal initial segment, it has been hypothesized that they underlie the generation of abnormal neuronal function in these diseases. We have studied certain aspects of this phenomenon through the use of a plant-derived indolizadine alkaloid, swainsonine, which specifically inhibits the lysosomal hydrolase, $\alpha$-mannosidase. These studies fully document the close morphological similarity between swainsonine-induced and inherited feline $\alpha$-mannosidosis. This includes the presence of clear and floccule-filled storage vacuoles, as seen with routine EM, and axon hillock neurite growth on select cell types, as seen with Golgi staining. The latter was found only on cortical pyramidal neurons and multipolar cells of amygdala, and these same cell types are known to be involved in ectopic neuritogenesis in other storage diseases. Combined Golgi-electron-microscopic studies demonstrated the presence of normal-appearing synapses on these aberrant neuritic processes and also unusual, membranous inclusions specifically within the neurite-bearing pyramidal cells. The latter may be indicative of unique metabolic changes in these neurons and is consistent with the hypothesis that storage of gangliosides or other glycolipids underlies the recapitulation of dendritic growth features in these diseases. Experimental manipulation of the disease process using the swainsonine model indicated that induction of cortical pyramidal neuron neurite growth could be influenced by both age of onset and intensity of intraneuronal storage. Although Golgi studies clearly demonstrated neuritic sprouting in animals with disease onset as late as at 1 year, cortical pyramidal cells of older, adult animals appeared to undergo significant storage without a similar induction of neurite growth. These studies support the view that induced neuritogenesis in neuronal storage disease is associated with changes in metabolism, specifically within the neurite-bearing cells, that this change possibly involves gangliosides, and that the neuritogenic response may be limited to pre-adult stages of brain maturation.

\footnotetext{
Received Oct. 10, 1986; revised June 29, 1987; accepted Aug. 4, 1987.

This work was supported by the NIH (NS 18804). We wish to thank Marie Buschke and May Huang for excellent technical assistance, Ms. V. Ahrens for manuscript preparation, and Drs. H. J. Baker and L. James for supplying the Astragalus plants.

Correspondence should be addressed to S. U. Walkley at the above address

Copyright (C) 1988 Society for Neuroscience $0270-6474 / 88 / 020445-13 \$ 02.00 / 0$
}

Inherited lysosomal hydrolase deficiencies in man and animals are known to be characterized not only by intraneuronal storage of select, undegraded metabolic products (Suzuki, 1976), but also by exuberant growth of new dendritic-like membrane (Purpura and Suzuki, 1976). The latter phenomenon has been studied in greatest detail in ganglioside storage disease and appears to occur specifically at the axon hillock region of select types of neurons, e.g., cortical pyramidal cells (Walkley and Pierok, 1986), whereas other cell types undergo storage but fail to demonstrate new growth processes (Walkley, 1987a). This ectopic growth of new membrane occurs in the form of axon hillock enlargements (meganeurites) and/or as secondary neuritic processes that sprout from axon hillocks or from meganeurites. Both meganeurites and secondary neurites often possess spines, and ultrastructural studies have demonstrated the presence of accompanying synapses. The majority of the latter are of asymmetric morphology (Purpura et al., 1978; Walkley et al., 1981b), but the origin of axons giving rise to these new contacts has yet to be established. These changes in neuronal geometry and connectivity have been hypothesized to be associated with abnormalities in ganglioside metabolism and/or storage and to be responsible for the neuronal dysfunction characteristic of these diseases (Purpura and Suzuki, 1976; Purpura, 1979; Walkley, 1987b).

Inherited animal models of neuronal storage disease have been used extensively in these studies on the pathobiology of storage disorders, and a more recent development is that of an inducible (and reversible) form of lysosomal hydrolase deficiency. The latter is accomplished with swainsonine, an indolizadine alkaloid found in "locoweed" (Astragalus) and "darling pea" (Swainsona) plants, which occur in the western United States and Australia, respectively (Dorling et al., 1978; Molyneux and James, 1982; Siegel et al., 1982). Swainsonine has been found to be an active site-directed, reversible inhibitor of lysosomal $\alpha$-mannosidase (Dorling et al., 1980) and also to inhibit Golgi membrane-associated $\alpha$-mannosidase (Tulsiani and Touster, 1983). Naturally occurring swainsonine intoxication in livestock has long been known to resemble inherited $\alpha$-mannosidosis (Hartley, 1971), and more recent studies at the electron-microscopic level have confirmed this impression (Walkley ct al., 1986). Further, Golgi studies of cerebral cortex in experimental swainsonine-induced $\alpha$-mannosidosis have revealed ectopic dendritogenesis, which appears identical at the light-microscopic level to that of inherited storage disease (Walkley and Siegel, 1985).

The present study has made use of experimental swainsonineinduced $\alpha$-mannosidosis and Golgi and combined Golgi-electron-microscopic methods as means of determining (1) the dis- 
Table 1. Animal identification and swainsonine treatment protocols

\begin{tabular}{llll}
$\begin{array}{l}\text { Animal } \\
\text { no. }\end{array}$ & $\begin{array}{l}\text { Dose } \\
\text { (IU } a / g m \\
\text { body wt/d) }\end{array}$ & $\begin{array}{l}\text { Age treatment } \\
\text { initiated }\end{array}$ & $\begin{array}{l}\text { Length of } \\
\text { treatment } \\
\text { (months) }\end{array}$ \\
\hline 1 & 50 & $1 \mathrm{~d}$ & 13.5 \\
2 & 100 & $3 \mathrm{~d}$ & 6.5 \\
3 & 75 & 2 weeks & 3.0 \\
4 & 100 & 2 weeks & 12.5 \\
5 & 100 & 3.5 months & 6.5 \\
6 & 100 & 5.0 months & 6.0 \\
7 & 100 & 8.5 months & 4.5 \\
8 & 100 & 12.0 months & 5.0 \\
9 & 100 & Adult & 4.0 \\
10 & 100 & Adult & 4.0 \\
11 & 100 & 3 weeks & 4.0 \\
12 & 200 & 3 weeks & 4.0 \\
\hline
\end{tabular}

${ }^{a} \mathrm{IU}$, inhibitory unit, defined in Materials and Methods.

tribution of ectopic dendritogenesis according to neuron type within the CNS (with comparison to studies of inherited neuronal storage disease), (2) the importance of age of onset of induced disease and relative intensity of intraneuronal storage vis-à-vis ectopic dendritogenesis, (3) the presence or absence of new synaptic contacts on ectopic dendritic membrane, and (4) the ultrastructural features of neurite-bearing pyramidal neurons.

A preliminary report on some of these data has appeared (Walkley et al., 1985).

\section{Materials and Methods}

Swainsonine was partially purified from dried locoweed (Astragalus) plants, using a water-extraction and Dowex column-separation technique described previously (Siegel et al., 1982; Walkley and Siegel, 1985). Samples containing $\alpha$-mannosidase inhibitory activity were pooled, quantitated, and frozen until used in feeding experiments. Quantitation of inhibitory activity was based on the determination of the amount of extract that would inhibit a standardized $\alpha$-mannosidase assay by $50 \%$, and this potency was expressed in terms of inhibitory units (IU) (Walkley and Siegel, 1985). Measured quantities of inhibitory units were administered according to weight of the animal and adjusted regularly with weight changes. Swainsonine preparations were given orally daily ( $6 \mathrm{~d} /$ week), using milk as a vehicle. All studies used kittens and young cats of known age and 2 adult cats (exact age unknown). Age-matched control animals were maintained in the same environment and were handled in parallel with treatment animals. An extensive literature on the cellular pathology of the CNS in inherited feline models of neuronal storage disease recommended the use of this same species for the induced studies. Dosage schedules for swainsonine administration and a listing of experimental animals used in this study are given in Table 1.

At the termination of treatment periods, animals were killed humancly by an overdose of sodium pentobarbital and tissucs fixcd immediately by cephalad-directed intracardiac perfusion of $3 \%$ glutaraldehyde- $2 \%$ paraformaldehyde in $0.1 \mathrm{~m}$ cacodylate buffer. Brains were removed, stored overnight in the same fixative (cold), and blocks of tissue processed for Golgi rapid and Golgi-chloral hydrate staining (Walkley, 1987a), or for combined Golgi-electron microscopy (Fairén et al., 1977). The latter method used small blocks of tissue that were impregnated by the Golgi rapid method and sectioned on a Vibratome. Neurons selected for further study were documented by drawing and/ or photography and subsequently dissected into smaller pieces of tissue suitable for processing. Each section of tissue containing an impregnated neuron was then gold-toned and deimpregnated. This involved incubation in cold $0.5 \%$ gold chloride $(15 \mathrm{~min})$, reduction in cold $0.05 \%$ oxalic acid $(2 \mathrm{~min})$, and deimpregnation with $1 \%$ sodium thiosulfate $(90 \mathrm{~min})$. Tissuc scctions werc subscquently dehydratcd, flat-cmbedded in Epon in BEEM capsules, thin-sectioned on an ultramicrotome, poststained with uranyl acetate and lead citrate, and examined on a Philips $300 \mathrm{EM}$. In addition to these studies, routine light-microscopic procedures [Nissl and hematoxylin-eosin staining on frozen and paraffin sections and toluidine blue and periodic acid-Schiff (PAS) staining on $2-\mu \mathrm{m}$-thick Epon sections] also were performed as a means of determining the degree and distribution of intraneuronal storage.

\section{Results}

\section{Clinical progression of induced disease}

Clinical manifestations of swainsonine-induced $\alpha$-mannosidosis consisted primarily of motor system abnormalities, and included wide-based stance and truncal ataxia, titubation, and foreleg spasticity. The latter sign was a prominent response to neck extension. There was no evidence for visual or auditory deficits, and hyperacusis was not observed. Onset of motor system dysfunction varied with dose and with the age at which treatment was initiated. Those animals dosed at 75-100 IU/gm body weight/d, with treatment initiated at 3.5 months or earlier (no.'s $2-5,11$ ), demonstrated clinical involvement after 8-12 weeks of swainsonine administration. This was evident initially as hesitation prior to jumping from a low resting bench to the floor, and progressed slowly to include the spectrum of motor system abnormalities described above. Those animals whose treatment was initiated at 5 months of age or older (at $100 \mathrm{IU} / \mathrm{gm}$ body weight/d; no.'s 6-10) and the animal treated at twice this dose (200 IU/gm body weight/d; no. 12) developed clinical signs earlier (4-8 weeks), and these tended to progress more rapidly. Gait abnormalities were generally more severe in these animals, particularly for the adult-onset pair (no.'s 9 and 10). The animal treated at $50 \mathrm{IU} / \mathrm{gm}$ body weight/d (no. 1) showed no clinical involvement until 8 months of swainsonine administration, and the signs progressed little prior to termination at over a year of age.

\section{Light- and electron-microscopic studies}

Routine light-microscopic analyses of frozen and paraffin sections revealed widespread neuronal vacuolation, with no area of brain appearing spared. Examination of toluidine blue-stained $2 \mu \mathrm{m}$ plastic sections of cerebral cortex revealed storage vacuoles in neurons of all layers and apparently in all cell types. The degree of storage was severest in the high-dosage animal (no. 12) and least in the low-dosage animal (no. 1) (Fig. 1). In the latter, intraneuronal storage was minimal and appeared to predominate in larger neurons of deeper cortical laminae. In the higher-dosage animals, however, all cortical neurons demonstrated some degree of storage. In the toluidine blue-stained $2-\mu \mathrm{m}$-thick Epon sections, the storage vacuoles typically appeared as clear, unstained, rounded profiles within the somata of neurons. On rare occasions neurons were observed that contained toluidine blue-positive inclusions; most commonly these cells were found in the vicinity of lamina III. Staining with PAS revealed a similar population of neurons, and these stood in stark contrast to surrounding cells which remained unstained (Fig. 2).

Ultrastructural studies of cortical neurons in all experimental animals appeared qualitatively similar. Storage vacuoles were clear or, more often, contained flocculent or fibrillar material, or smaller vacuoles (Fig. 3). Rarely, routine electron microscopy demonstrated neurons containing large numbers of storage inclusions characterized by loose stacks of short membranous leaflets. The Golgi apparatus, endoplasmic reticulum, and other 
A

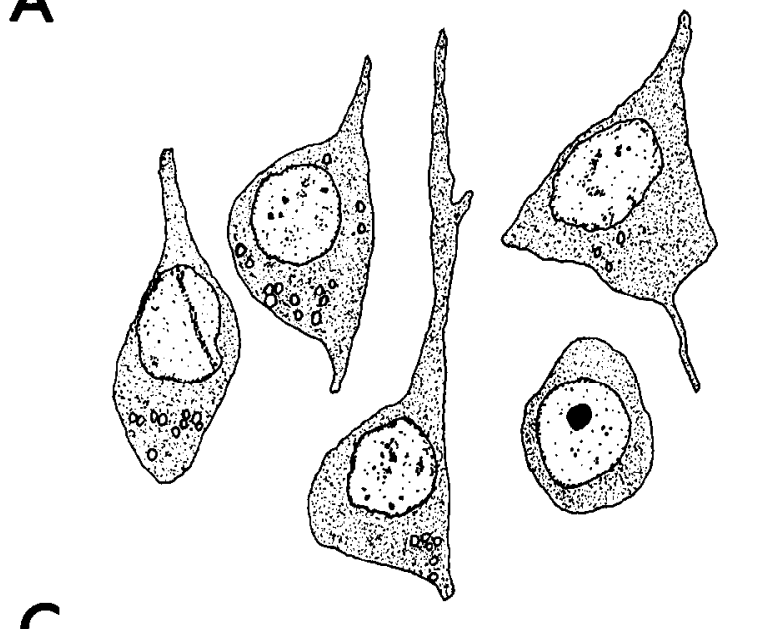

C
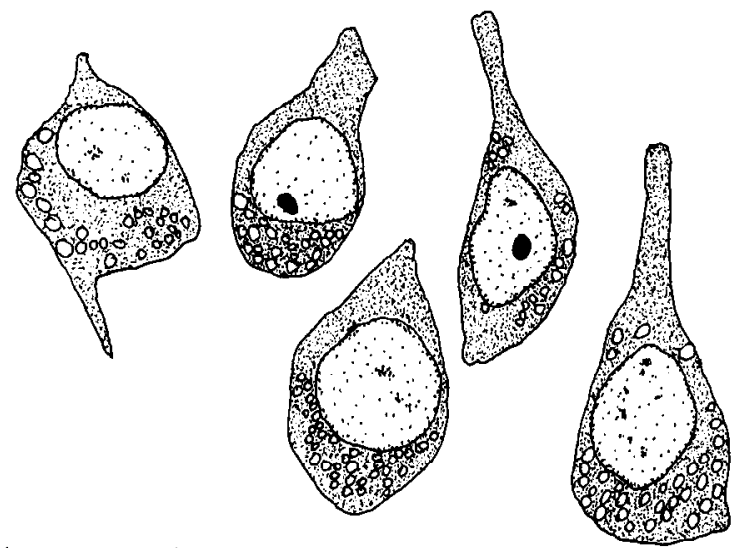

B
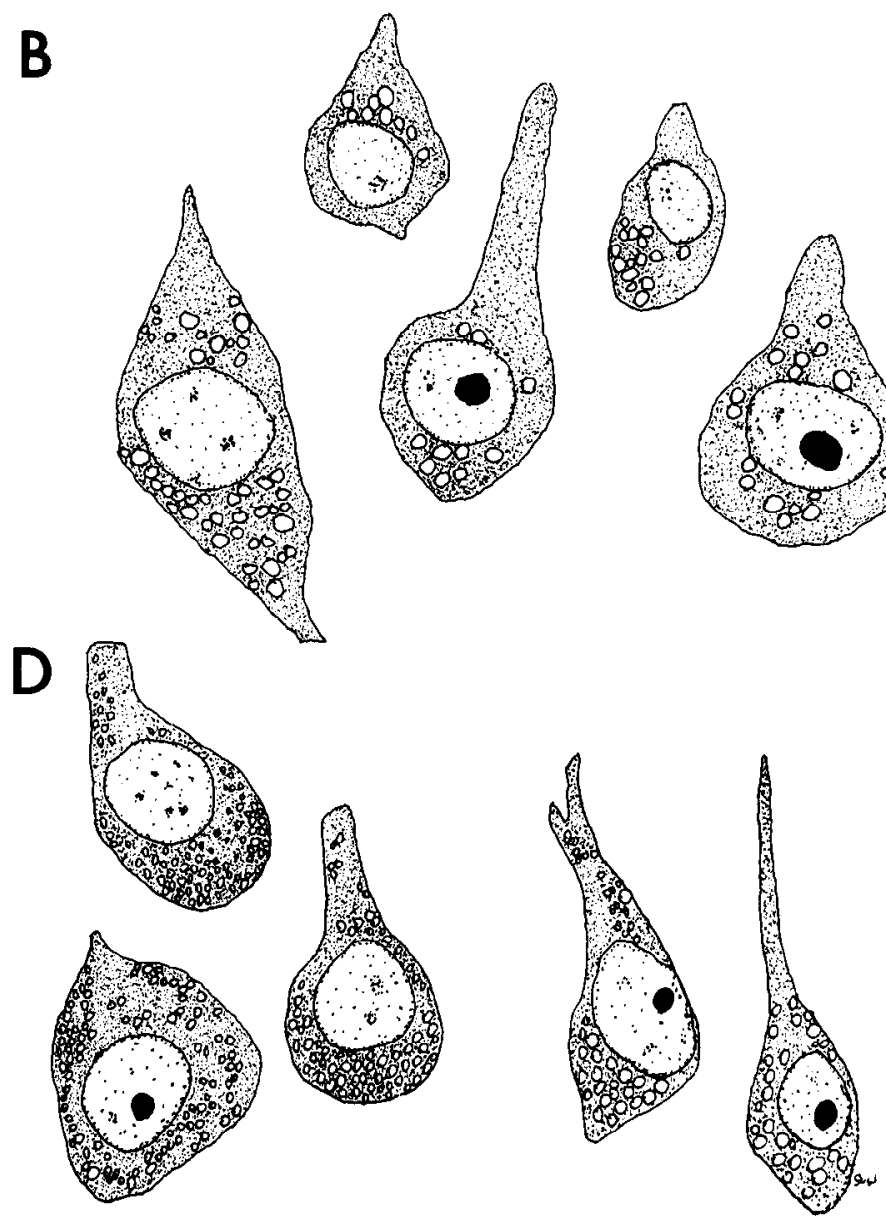

Figure 1. Camera lucida drawings of cortical neurons, illustrating the number and distribution of intrasomatic storage vacuoles following swainsonine administration at different dosages and for different treatment periods. $A$, Animal no. 1, treated at $50 \mathrm{IU} / \mathrm{gm}$ body weight/d for $13.5 \mathrm{months}$. $B$, Animal no. 4, treated at twice the dosage as that shown in $A(100 \mathrm{IU} / \mathrm{gm}$ body weight/d), but for a similar period of time (12.5 months). $C$, Animal no. 11, treated at $100 \mathrm{IU} / \mathrm{gm}$ body weight/d for 4 months. $D$, Animal no. 12 , treated at twice the dosage as that shown in $C$, but for the same time period. Storage vacuoles were more numerous and more widely distributed in the latter than in lower-dosage animals. Calibration bar, $20 \mu \mathrm{m}$.

organelles were commonly observed in cells and displayed no conspicuous abnormalities.

Successful Golgi impregnations were achieved in cerebral cortex for all animals outlined in Table 1. In addition, Golgi data were obtained for basal ganglia and other subcortical areas, thalamus, and cerebellum for many of these animals. Golgi staining revealed neurons that were either normal-appearing or slightly swollen with rounded somatic contours. Neurons with enlarged axon hillocks bearing neurites or with spiny meganeurites were limited in distribution and found only on 2 cell types. These were pyramidal neurons of cerebral cortex and multipolar cells of the amygdala (Figs. 4, 5). Other cell types in these brain regions, as well as medium spiny cells of caudate, type 1 cells of thalamic relay nuclei, and all major cell types of cerebellum, did not demonstrate ectopic growth processes or meganeurites, or other distortions of the soma-axon hillock area.

In cerebral cortex, axon hillock neurite growth and spiny meganeurites were most often seen on robust, layer III pyramidal cells and occasionally on similar neurons in layer $\mathrm{V}$ (Figs. $4, A, B ; 5 A)$. The somata of these cells were triangular in shape with a base width of $12-30 \mu \mathrm{m}$ and a height of $20-40 \mu \mathrm{m}$. They possessed 4-6 large-diameter basilar dendrites and, most commonly, a single, prominent apical dendrite that appeared to reach into or past laminae II. They were distributed widely throughout many gyri, but a common site of occurrence was the lateral ectosylvian gyrus. Although strict quantitative evaluation of the incidence of neurite-bearing cells could not be achieved with Golgi staining, cells of this type were most readily demonstrated in the animal administered the highest swainsonine dose (no. 12). Figure 6 shows a camera lucida reconstruction of 3 representative Golgi-stained sections from one area of the suprasylvian gyrus of this animal, and demonstrates the relative incidence of neurite-bearing and normal-appearing pyramidal and nonpyramidal neurons. Neurite and spiny meganeuritebearing cells were encountered at no more than half this frequency in lower-dose animals. Thus, ectopic neurite growth was not a common finding; as such, this induced disease closely resembled inherited feline $\alpha$-mannosidosis (Walkley et al., 1981a). However, with the notable exception of the 2 adultonset storage disease animals (no.'s 9 and 10), cortical pyramidal neuron ectopic neurite growth was detected to some degree in all treatment animals. In the lowest-dose animal (no. 1), actual neurite growth was quite rare and, more commonly, axon hillocks of layer III pyramidal neurons appeared slightly enlarged and possessed only occasional spine-like processes.

Axon hillock enlargements without spines or neurites (aspiny 

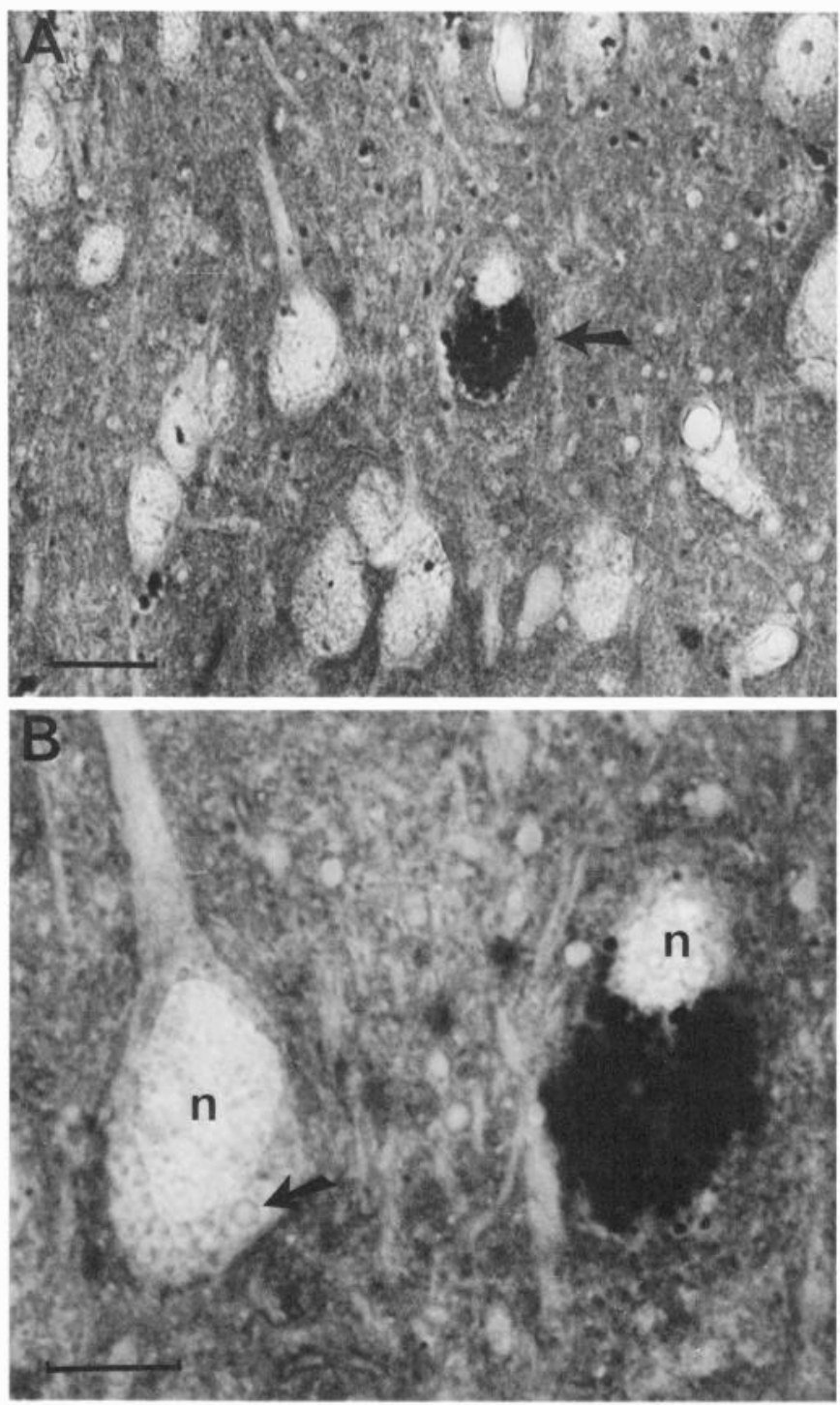

Figure 2. Photomicrographs of PAS staining of $2 \mu \mathrm{m}$ plastic sections from the cerebral cortex of animal no. 12. Only rarely were PAS-reactive cells encountered, and these were located primarily in the lamina III region $(A$, arrow). Higher-power examination of these neurons revealed the presence of discretely stained storage vacuoles that contrasted sharply with those of adjacent cells that remained unstained $(B$, arrow). Toluidine blue staining gave similar results. $n$, Nucleus of cell. Calibration bar: $20 \mu \mathrm{m}(A) ; 10 \mu \mathrm{m}(B)$.

meganeurites) also were encountered on occasional cortical pyramidal neurons in all treatment animals, including those with adult-onset disease (Fig. $4 C$ ). At the electron-microscopic level, meganeurites were found to contain storage inclusions similar to those seen in adjacent somata.

Alterations in dendritic arbors of some cortical neurons also were observed in this study. These abnormalities consisted of focal, spherical enlargements at branch and nonbranch portions of apical and basilar dendrites (Fig. 7) and occurred on both pyramidal and nonpyramidal cells. Normal-appearing spines were often present on these swellings, and segments of dendrites distal to the enlargements most commonly appeared normal. Ultrastructural studies revealed abnormal dendritic profiles that appeared to correspond to changes seen with Golgi staining (Fig. 7). Invariably, these enlargements contained large vesicular structures of unknown origin, whereas mitochondria and other cellular organelles appeared normal in number and form. Microtubules were not readily discernible within the dendritic spheroids, but often were seen in adjacent, normal-appearing dendritic segments. Normal-appearing synapses were seen in association with dendritic swellings, and occurred on both spines and shafts.

In addition to the above-described changes in soma-dendritic domains of neurons in swainsonine-induced $\alpha$-mannosidosis, axonal abnormalities also were noted. These consisted of spherical enlargements located within several hundred microns of associated cell somata, or deeper in white matter areas. They were characterized ultrastructurally by the accumulation of large numbers of mitochondria, multivesicular bodies, and other organelles, and could be readily distinguished from the somadendritic abnormalities described above.

\section{Combined Golgi-electron-microscopic studies}

Layer III pyramidal neurons displaying axon hillock neurite growth in animal no. 12 were examined ultrastructurally and data from one cell are displayed in Figure 8. Similar results were obtained for all neurons processed in this manner. Golgi staining of this cell demonstrated small, apparently branching neurites and numerous spines at the axon hillock-initial segment region. The cell soma and axon hillock were slightly enlarged. Ultrastructural examination revealed cytoplasmic storage vacuoles that appeared to be filled with membrane leaflets, flocculent material, and smaller vacuoles (Fig. $8 C$ ). The membranous components appeared in considerable excess of that observed by routine electron microscopy in the vast majority of cortical neurons in this and other experimental animals used in this study. Gold-toned profiles corresponding to ectopic neurites seen at the light level were easily distinguished in the neuropil adjacent to the axon hillock. Prominent synapses were visible on these neuritic processes (Fig. 8, D, E), as well as on neuritic and axon hillock spines. These synapses generally displayed a conspicuous postsynaptic density and could be classified as being asymmetrical.

The plasmalemma of this and other neurons examined in this study appeared normal and did not possess outpocketings and other irregularities, as have been observed with Golgi-electronmicroscopic studies of pyramidal neurons in ganglioside storage disease (Walkley et al., 1981b).

\section{Discussion}

The studies reported here fully establish the close morphological similarity between swainsonine-induced $\alpha$-mannosidosis and an inherited deficiency of the same enzyme. Most noteworthy in this regard were the presence of ultrastructural changes and of meganeurites and ectopic, axon hillock-associated neurites that appeared identical to inherited $\alpha$-mannosidosis (Walkley et al., 1981a; Vandevelde et al., 1982). The ultrastructural characteristics of swainsonine-induced storage appeared fully consistent with inhibition of lysosomal $\alpha$-mannosidase, and this finding was similar to that of a recent report on swainsonine-induced visceral storage in the rat (Novikoff et al., 1985). Given this remarkable similarity between induced and inherited $\alpha$-mannosidosis, the experimental manipulations of the disease process carried out in this study can be expected to provide valid insight into those factors controlling the expression of ectopic dendritogenesis and altered connectivity that characterize these disorders. Indeed, results of this study bear directly on hypotheses 


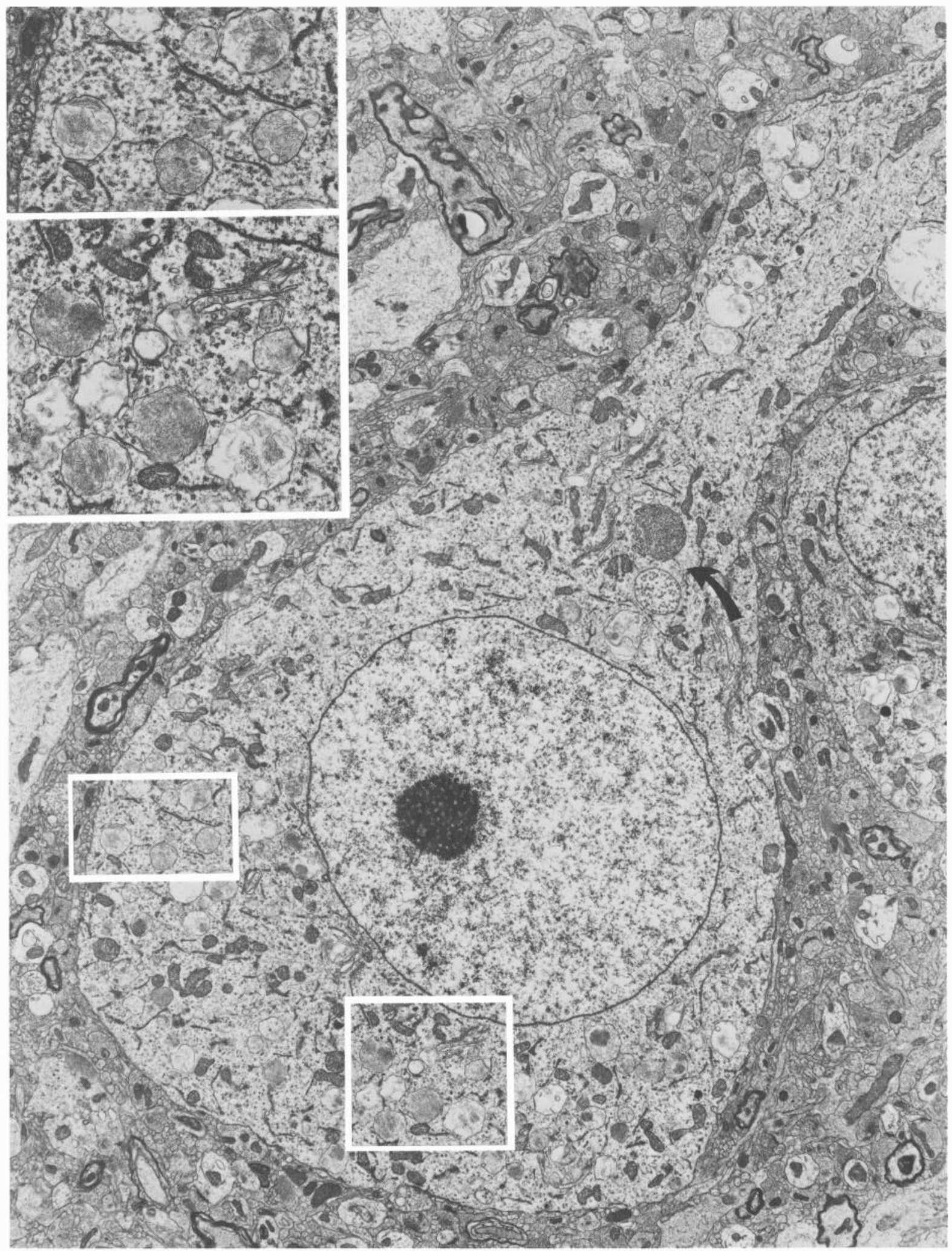

Figure 3. Electron micrograph of pyramidal-like neuron from cerebral cortex of animal no. 2, illustrating typical intraneuronal vacuolation. Most storage inclusions (see insets) appear to be filled with fibrillar, floccular or vacuolar materials. Two giant multivesicular-like bodies can also be seen in this cell at the base of the apical dendrite (arrow). The nature of these unusual structures is unknown. They have also been reported in feline mucopolysaccharidosis (Haskins et al., 1983), but we found similar structures in normal cats used in this study. $\times 6500$; insets, $\times 14,400$. 

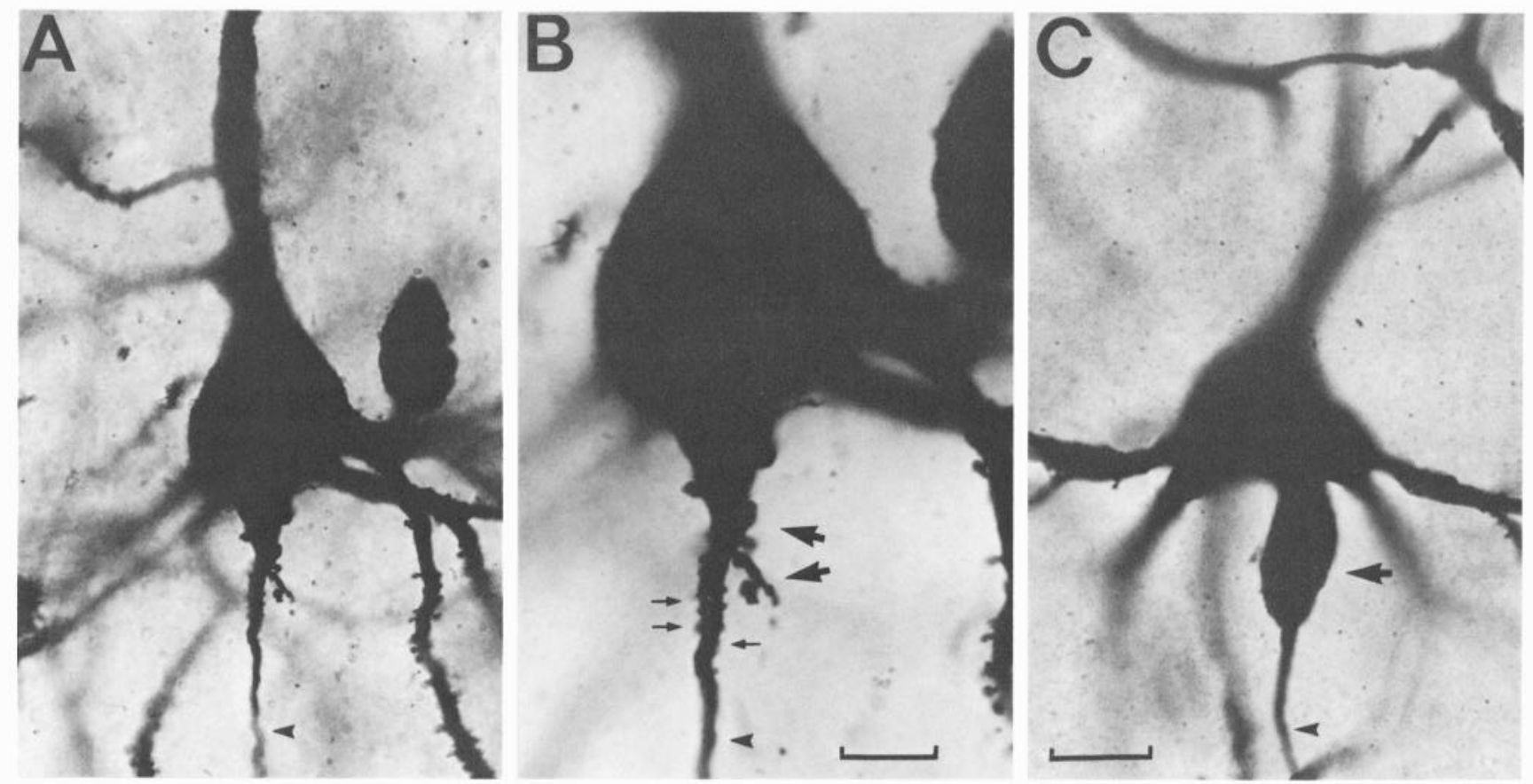

Figure 4. Photomicrographs of Golgi-impregnated layer III cortical pyramidal neurons in swainsonine-induced $\alpha$-mannosidosis. $A$ and $B$ are different magnifications of the same cell from animal no. 8, illustrating ectopic, axon hillock neurites (large arrows) and numerous spines (small arrows). $C$, A neuron displaying an axon hillock that has expanded considerably with the formation of a neck between the enlargement (or meganeurite, arrow) and the soma. This meganeurite bears no spines or neurites. Arrowheads indicate axons. Calibration bars: $20 \mu \mathrm{m}(C$, also applies to $A$ ); 10 $\mu \mathrm{m}(B)$.
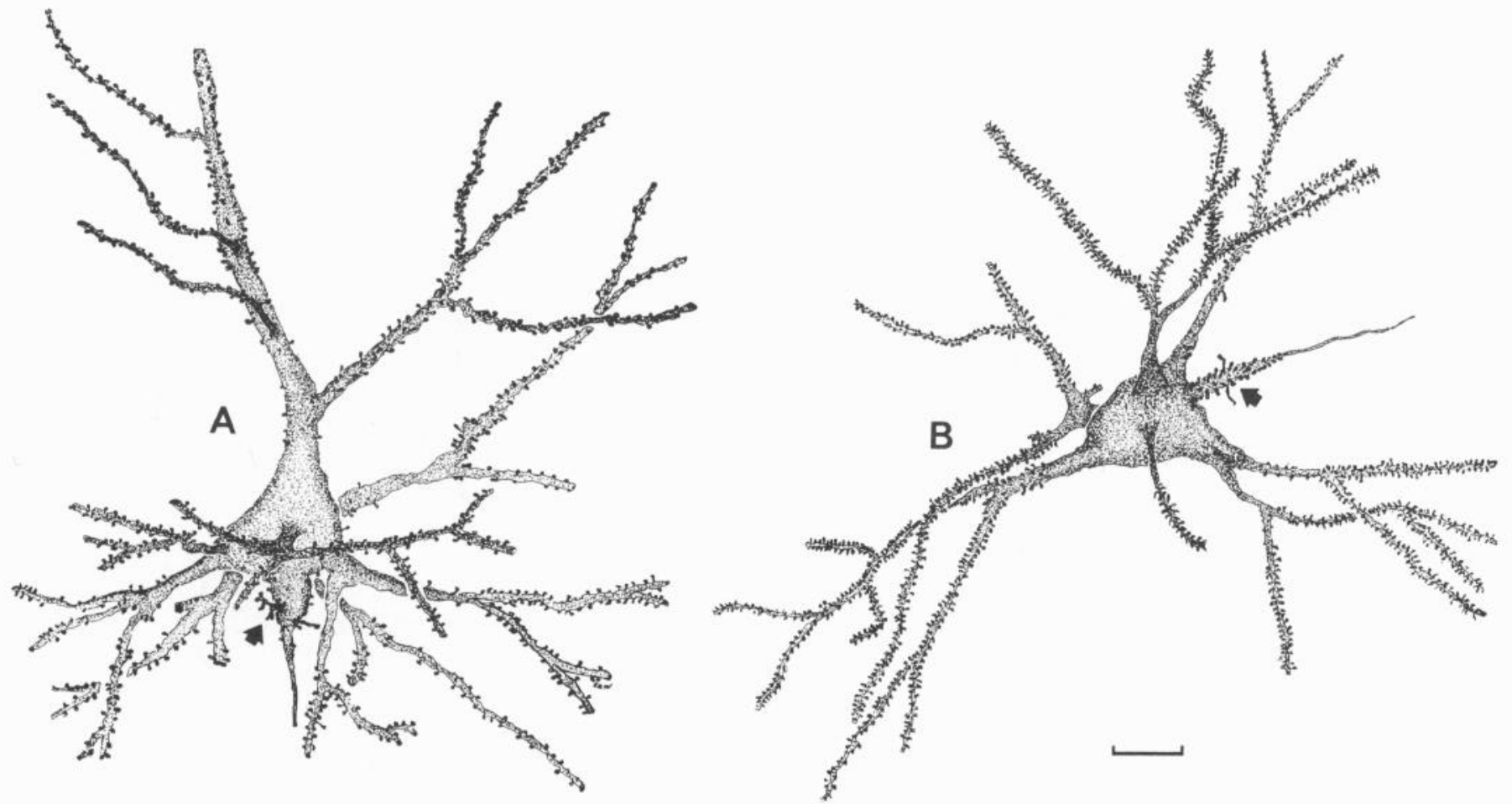

Figure 5. Camera lucida drawings illustrating ectopic axon hillock neurites and spines in swainsonine-induced $\alpha$-mannosidosis. $A$, Layer III cortical pyramidal neuron from the suprasylvian gyrus (animal no. 12), demonstrating an enlarged axon hillock and ectopic neurites. One of the latter appears to be branched or to be covered with spines (arrow). B, Multipolar cell from the amygdala (animal no. 3), illustrating exuberant axon hillock-initial segment spines and 2 longer neuritic processes (arrow). Calibration bar, $20 \mu \mathrm{m}$. 


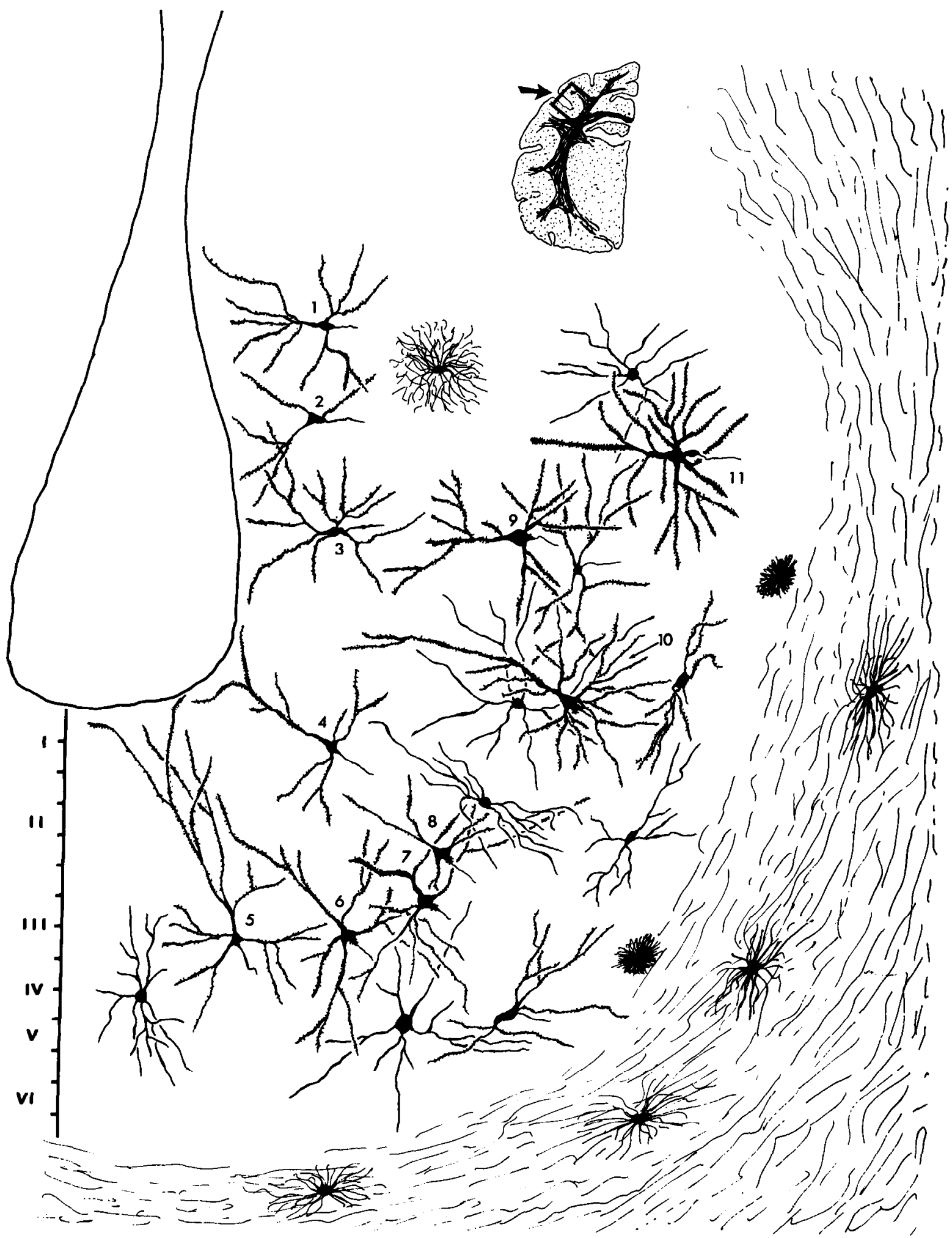

Figure 6. Camera lucida drawing of Golgi-impregnated cortical neurons of the lower suprasylvian gyrus (see inset) as compiled from several adjacent sections (animal no. 12). The relative incidence of a variety of morphological changes is shown. Cells $6-10$ demonstrate various degrees of axon hillock neurite growth; cell 11 has a large, aspiny meganeurite; whereas other pyramidal neurons (1-5) appear essentially normal. Several basket and other intrinsic cells are also shown and appear normal or slightly enlarged. Routine histological studies have indicated that all of these cells would possess some degree of cytoplasmic vacuolation. Calibration bar at left is in steps of $100 \mu \mathrm{m}$. The cell shown at 10 is illustrated in greater detail in Figure $5 A$. 
Figure 7. Electron micrograph and (see inset) photomicrograph of Golgi stain illustrating spheroid formation within dendrites in swainsonine-induced $\alpha$-mannosidosis (animal no. 6). The Golgi stain reveals 2 focal areas of enlargement (arrows), both of which possess several small, dendritic spines. In the electron micrograph these enlargements appear to coincide with focal swellings containing dilated vesicular structures of unknown origin (long arrow) and a paucity of normal-appearing microtubules. Spines and normal-appearing synapses could also be seen in association with focal enlargements at the electron-microscopic level (short arrow). Inset, $\times 400$; electron micrograph, $\times 11,200$.
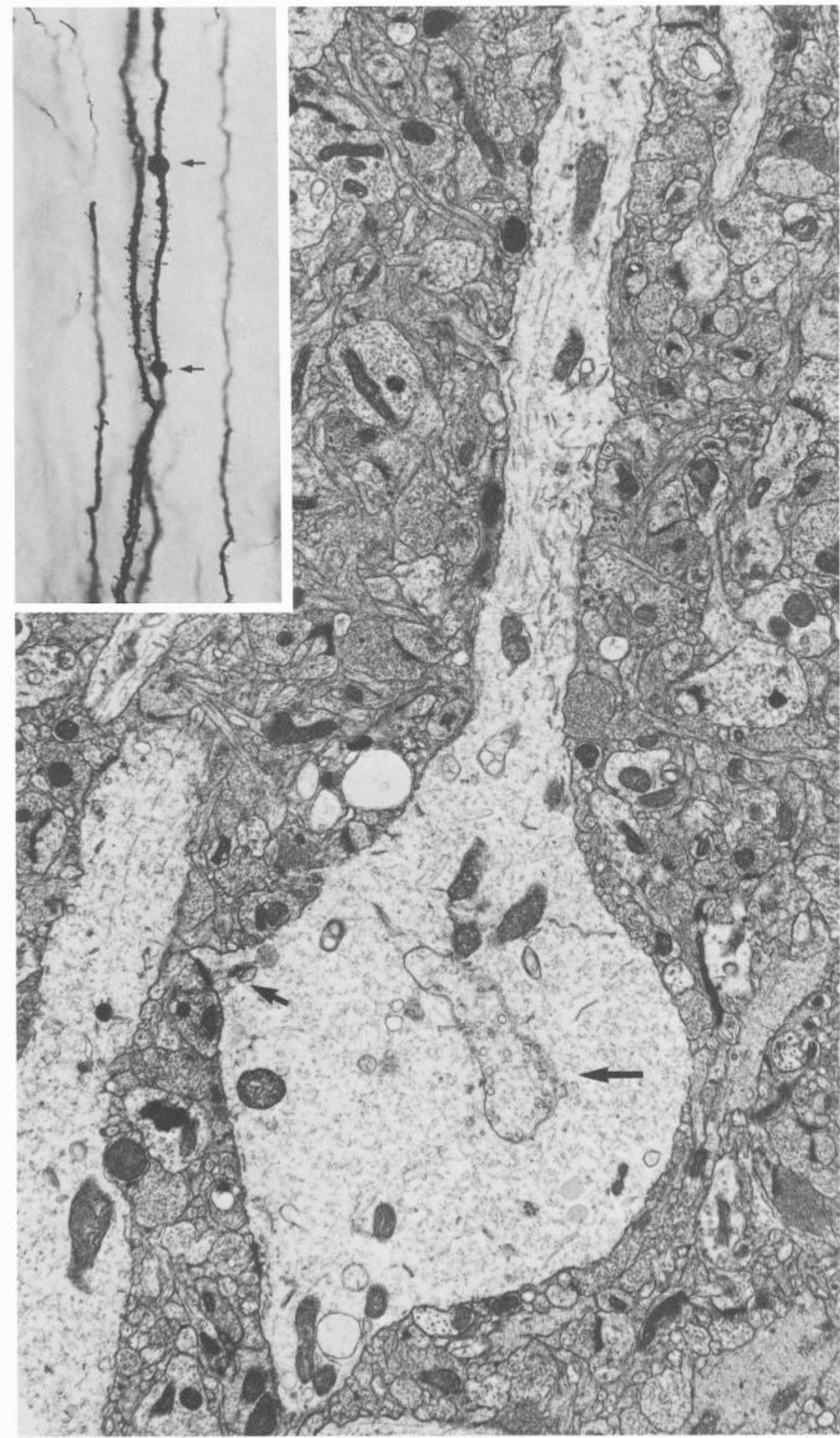

of meganeurites, secondary neurites, and altered synaptic connectivity. This exuberant production of new, dendritic-like membrane was hypothesized to result from the presence of a

neurite-inducing factor that was considered most likely to be a concerning the pathogenesis of neuronal storage disorders, as developed by Purpura and colleagues (Purpura and Suzuki, 1976; Purpura and Walkley, 1981). These hypotheses grew out of the initial Golgi studies on storage diseases and the discovery

Figure 8. Combined Golgi-electron-microscopic study of layer III cortical pyramidal neuron in swainsonine-induced $\alpha$-mannosidosis (animal no. 12). A, Camera lucida drawing illustrating enlarged axon hillock, numerous spines, and branched and nonbranched neurites (arrow). Inset, a photomicrograph of the same neuron in glycerin mount prior to gold-toning and deimpregnation. Calibration bar, $10 \mu \mathrm{m}$. $B$, Low-power electron micrograph showing storage vacuole-filled soma outlined by gold stippling, with detached gold-labeled neuritic profiles adjacent to axon hillock $(b o x) . \times 8000$. $C$, Higher magnification of typical intrasomatic storage vacuoles consisting primarily of loose stacks of membranes $(\times 18,600)$. $D$, 

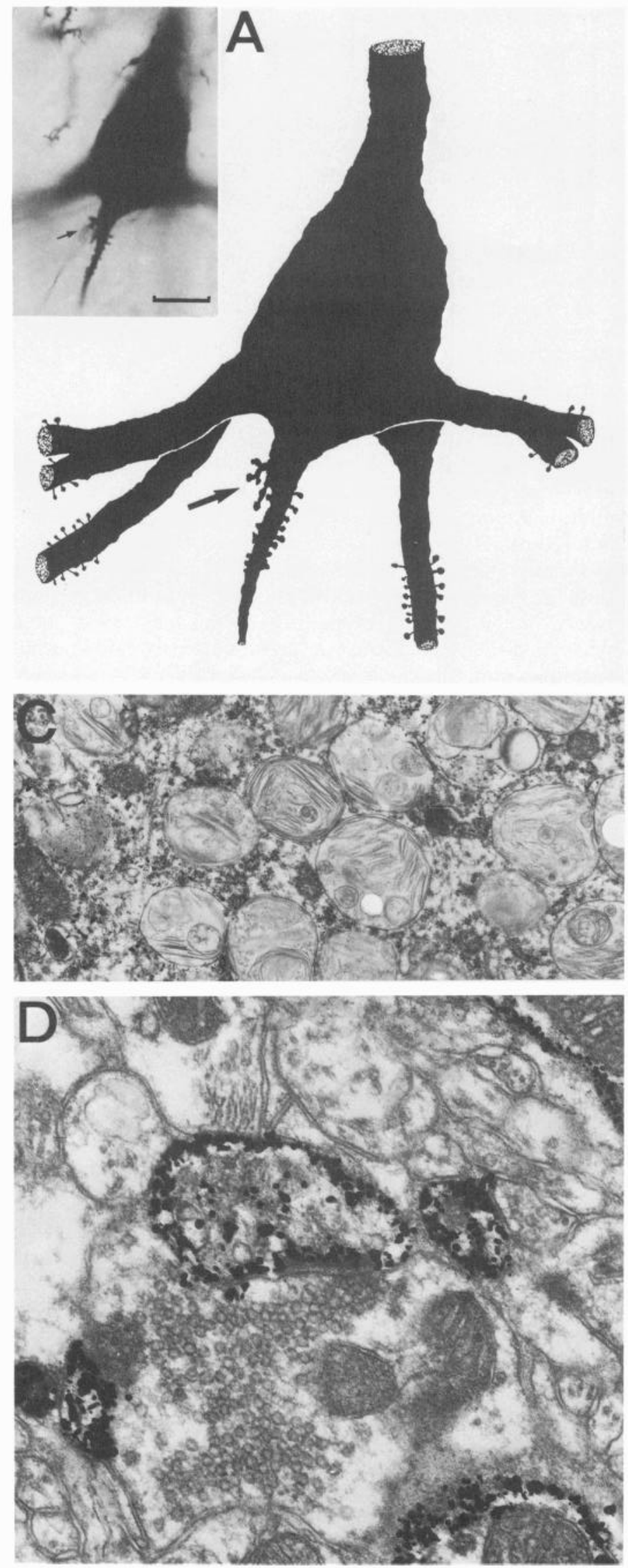
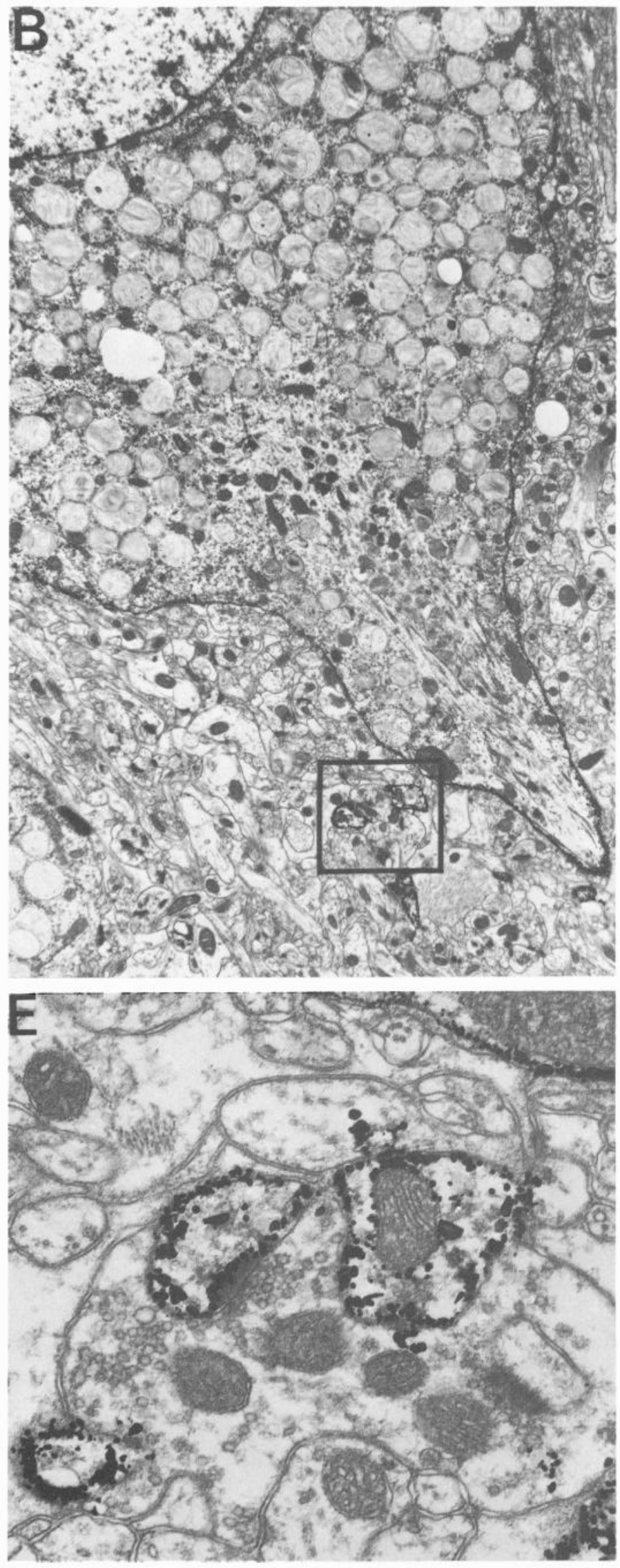

$E$, Higher magnification of neuritic profiles seen in $B$ (box) in semiadjacent sections. Synapses with prominent postsynaptic densities are evident. $\times 41,850$. 
ganglioside. Further, the distortion of normal neuronal shape with the growth of meganeurites, and the influence of ectopic synaptic input near the axonal initial segment were believed to provide a basis for neuronal dysfunction in these diseases. This latter view largely supplanted the prevailing logical assumption that cell dysfunction in storage diseases resulted from simple crowding of normal organelles and eventual "cytotoxic" effects (Desnick et al., 1976).

\section{Changes in neuronal morphology}

Results of Golgi studies of swainsonine-induced $\alpha$-mannosidosis reported here (apart from the low-dose and 2 adult animals, no.'s 1, 9, and 10, respectively) appear essentially indistinguishable from an earlier report on inherited feline $\alpha$-mannosidosis (Walkley et al., 1981a). Axon hillock neurite growth, although an uncommon finding, was nevertheless a striking feature of those cells so affected. These neurons commonly were large, robust pyramidal cells of layer III and occasionally layer V. Although they could be found in all parts of the neocortex, one area where they were encountered regularly was the lateral ectosylvian gyrus. In cats this cortical region is known to be associated with auditory function (Mitani et al., 1985), and the neurite-bearing pyramidal neurons in this area appeared similar to those medium and large pyramids of laminae III and V, as recently described in detail in normal cat auditory cortex (Winer, 1984). The more elongated small pyramids of this region, also described by Winer, appeared uninvolved in neurite growth.

Although qualitatively identical ectopic, axon hillock-associated neurite growth has been described on cortical pyramidal neurons in a wide variety of neuronal storage disorders (GMI and GM2 gangliosidosis, mucopolysaccharidosis, and sphingomyelin lipidosis) (Purpura and Baker, 1978; Walkley and Haskins, 1982; Walkley and Baker, 1984; Walkley, 1987b), in no disease other than $\alpha$-mannosidosis has the distribution of neurite growth been so confined. For example, in the gangliosidoses, both layers II and III pyramidal cells commonly display neurite growth. The distribution of ectopic neurites is somewhat less extensive in the other storage diseases mentioned, but is still more frequently encountered than in $\alpha$-mannosidosis. Additionally, the degree of neurite growth on individual cells seems to follow a similar pattern, i.e., it is most prolific on pyramidal neurons in the gangliosidoses and least extensive in $\alpha$-mannosidosis.

Studies reported here also demonstrate that multipolar cells of the amygdala undergo a similar process of neurite and spine elaboration at the axon hillock region. Golgi studies are not yet available for this region in inherited $\alpha$-mannosidosis, but data consistent with this finding are available for GM1 gangliosidosis (Walkley, 1986) and sphingomyelin lipidosis (Walkley and Baker, 1984). This similarity of distribution of neurite growth in different storage diseases appears to indicate that the same limited types of neurons are capable of ectopic neuritogenesis regardless of the specific lysosomal hydrolase defect (Walkley, 1987b).

In addition to this parallel incidence of ectopic neurite growth in induced and inherited neuronal storage diseases, changes involving axonal pathology also appear similar. Axonal spheroids indistinguishable from those reported here have also been seen in inherited feline $\alpha$-mannosidosis (Vandervelde et al., 1982), as well as in other animal and human storage disorders (Jolly, 1971; Suzuki, 1976; Lovell and Jones, 1985; Walkley, 1987b).
The ultrastructural characteristics of these spheroids appear remarkably similar across this spectrum of storage diseases and also closely resemble those described for neuroaxonal dystrophy (Jellinger, 1973). The pathogenetic mechanisms underlying development of these axonal changes, and their functional consequences, are unknown.

Dendritic spheroids have also been described here for swainsonine-induced $\alpha$-mannosidosis, and these appear to be identical to those seen in inherited feline $\alpha$-mannosidosis. Although occasional swellings are seen within dendrites in other types of neuronal storage disorders (Walkley, 1987b), the common presence of focal, spherical enlargements as reported here have not been described elsewhere. Again, as with axonal spheroids, the mechanism of the genesis and functional consequences of this change are unknown.

\section{Combined Golgi-electron-microscopic studies}

Ultrastructural studies in combination with Golgi staining have proved successful for elucidating changes in individual pyramidal neurons in storage disease. As reported here, swainsonineinduced neurite growth has been examined with this technique and normal-appearing synapses identified in contact with their surfaces. As with similar studies using the felinc GM1 gangliosidosis model (Walkley et al., 1981b), the majority of these synapses displayed a distinct postsynaptic density and thus appeared asymmetrical.

A second finding in these studies using the swainsonine model was the presence of unusual storage vacuoles within those neurons bearing ectopic neurites. Golgi studies have revealed that the vast majority of neurons in cerebral cortex in $\alpha$-mannosidosis do not possess ectopic neurites even in advanced disease, and routine electron microscopy has demonstrated that these cells commonly contain storage vacuoles that appear clear, floccular, or vesicular. However, in the present study neurite-bearing pyramidal neurons, without exception, have been found to possess storage vacuoles containing membranous components. These appeared as leaflets of membrane that occurred singly or in loose stacks. As such, these inclusions appeared similar to those in the glycolipid and some other storage diseases. Membranous swirls (membranous cytoplasmic bodies; mcbs) that characterize the gangliosidoses (Terry and Weiss, 1963) have not been seen, but zebra body-like aggregations of membranes characteristic of mucopolysaccharidoses (Suzuki, 1976) have been identified. Interestingly, all of the neuronal storage disorders that have to date been characterized by pyramidal neuron neurite growth have the presence of membranous storage vacuoles in common. These include the gangliosidoses and sphingomyelin lipidosis (with mcbs) and mucopolysaccharidosis (with zebra bodies). All of these diseases also have in common the presence of some degree of ganglioside storage, either as a direct or indirect consequence of the primary metabolic defect (Baker et al., 1971; Cork et al., 1977; Constantopoulos et al., 1980; Wenger et al., 1980). It is therefore a notable finding that in feline $\alpha$-mannosidosis, an oligosaccharide and glycoprotein storage disorder (Beaudet, 1983), neurite-bearing pyramidal cells contain membranous inclusions suggestive of possible ganglioside or other glycolipid accumulation. Additional evidence for this comes from light-microscopic study of toluidine blue- and PAS-stained $2 \mu \mathrm{m}$ plastic sections of cerebral cortex of cats used in this study. In each case a small subpopulation of cortical neurons was revealed that contained storage vacuoles that stained intensely with toluidine blue or PAS. As such, these cells closely 
resembled those routinely encountered in the lipidoses, where ganglioside or other glycolipid storage is commonly observed. Similar toluidine blue-positive inclusions have recently been reported in occasional cortical neurons in inherited feline $\alpha$-mannosidosis (Blakemore, 1986). The overall distribution, frequency of occurrence, and staining characteristics of these cells suggest that they may be equivalent to those cells recognized with the Golgi-electron-microscopic technique as containing membranous inclusions and possessing neurite growth. Additional studies to confirm this correlation and to determine the chemical nature of these unusual inclusions are in progress.

The presence of membranous inclusions in neurite-bearing neurons suggests that unique metabolic events are occurring in these cells relative to their neighbors. Such inclusions also are consistent with Purpura's original hypothesis, which stated that it was the presence of gangliosides or closely related glycolipids that was in some way related to renewed neuritogenesis (Purpura, 1979). Presumably, as in the case of GM1 gangliosidosis, the presence of excess ganglioside in storage vacuoles indicates likely alterations in ganglioside constituents elsewhere in the neuron. That is, elevated levels of GMl ganglioside have been found in synaptosomal plasma membrane fractions in GM1 gangliosidosis (Wood et al., 1985). If gangliosides or other glycolipids are somehow involved in the process of renewed neuritogenesis, it is likely that this is due to their presence in abnormal amounts or locations in physiologically active regions of the cell other than lysosomal storage vacuoles. The actual mechanism by which such changes in ganglioside metabolism could result in ectopic neuritogenesis is unknown. However, studies in recent years in which gangliosides were applied to neuronal culture systems have clearly shown the presence of a neuritogenic response (Roisen et al., 1981; see Ledeen, 1984, for review). These data suggest that exogenous gangliosides are incorporated into neuronal cell membranes and act as acceptor molecules for growth-promoting factors present in the media. In a related work, Yavin and co-workers have reported that gangliosides added to a somatic neurohybrid clonal cell line result in significantly increased mRNA sequences for tubulin (Rybak ct al., 1983). This finding is consistent with the view that gangliosides can regulate cellular gene expression for $\mathrm{cy}$ toskeletal elements presumably essential for neurite outgrowth. However, the exact relationship between findings of this type in simple culture systems and the considerably more complex nature of mammalian cerebral cortex remains to be determined.

\section{Experimental manipulation of storage disease}

As swainsonine-induced $\alpha$-mannosidosis appears to closely mimic inherited $\alpha$-mannosidosis, varying certain aspects of disease intensity (i.e., the dose level of administered swainsonine) or age of onset of storage may provide insight into pathogenetic events. The studies reported here indicate that both age of onset of disease and intensity of storage have important consequences for clinical involvement and for induction of ectopic neuritogenesis. Ectopic neurites were not observed in the 2 adult animals used in this study, although they were present in all other experimental animals (except no. 1, the lowest-dose animal). Clearly, caution must be used in interpreting this type of negative data, as Golgi staining does not allow for absolute proof of the absence of neurite growth. Additionally, PAS staining of Epon sections and routine EM studies did reveal several examples of neurons with lipid-like inclusions in these older animals. In a related work, Golgi staining of cerebral cortex from adult livestock that were chronically intoxicated with swainsonine consumed as locoweed (Astragalus) plants demonstrated a similar absence of neurite growth, although large, aspiny meganeurites were much more commonly seen than in the feline model (Walkley and James, 1984). Clearly, additional studies will be needed to determine whether the neuritogenic response of pyramidal neurons is characterized by a specific developmental window.

Evidence for the potential development of meganeurites regardless of age is substantial. Meganeurites have not only been observed in adult-onset $\alpha$-mannosidosis in this study and in the one described above (Walkley and James, 1984), but also in studies of aged human cortex following lipofuscin accumulation (Braak et al., 1980; S. U. Walkley and R. D. Terry, unpublished observations). Under these circumstances, meganeurites have invariably appeared aspiny. Whether these structures represent sites of new synapse formation like those of ectopic neurites and spiny meganeurites remains to be determined, but in at least one storage disease characterized by aspiny meganeurites (infantile neuronal ceroid lipofuscinosis), these structures were reported to be free of new synaptic contacts (Williams et al., 1977).

Studies reported here clearly indicate that the maximal neuritogenic response in swainsonine-induced $\alpha$-mannosidosis was not achieved by earlier onset of storage. Indeed, neurite growth in dose-matched animals ( $100 \mathrm{IU} / \mathrm{gm}$ body weight/d), with onset varying from $3 \mathrm{~d}$ to 12 months, actually appeared somewhat more common in the older animals. Age of onset also appeared to influence the clinical course, with animals 5 months or older at initiation of treatment appearing to compensate less effectively than younger animals. The reason for this is not clear. Clinical signs consisted primarily of cerebellar deficits (titubation and ataxia) across all age groups. Seizure activity was not seen in any of these animals, and clinical problems resulting specifically from cerebral cortical storage were not evident. This was in spite of significant intraneuronal storage in cortical neurons.

Another factor that appeared to have considerable influence over clinical disease and neurite growth was the swainsonine dose level. Effects of the disease clearly could be "titrated" by varying the intensity of treatment. This was evident for clinical signs that were of more rapid onset and greater severity at the higher dose level ( $200 \mathrm{IU} / \mathrm{gm}$ body weight/d). This was also the case for pyramidal neuron neurite growth, as this phenomenon appeared considerably more abundant in the higher-dose animal. However, the types of neurons demonstrating neurites were the same; additional types of cells did not appear to be recruited into the process of neurite elaboration.

In addition to the initiation of ectopic neuritogenesis in storage diseases, neurite elongation and new synapse formation must also be considered. Studies reported elsewhere using the swainsonine model have suggested that regardless of the metabolic event that initiates neurite growth, the reversal of the disease process (through swainsonine withdrawal) does not lead to the immediate loss of the new dendrites or their connections. Indeed, these related studies suggest that, once initiated, the ectopic neuritic processes continue to elongate and to maintain established synaptic contacts in the face of disease correction (Walkley et al., 1987).

The studies reported here clearly reveal that swainsonineinduced $\alpha$-mannosidosis offers a means of unraveling important events in the pathobiology of neuronal storage disease. Understanding the basis for neuronal dysfunction in this family of 
disorders is of paramount importance for the eventual development of any successful therapies for these diseases. Furthermore, understanding those factors responsible for induction of new axon hillock-associated neurite growth and altered connectivity - phenomena apparently unique to the storage diseases-may lend insight into the factors controlling dendritogenesis and the modifiability of connections in normal nervous systems.

\section{References}

Baker, H. J., J. R. Lindsey, G. M. McKhann, and D. F. Farrell (1971) Neuronal GM1 gangliosidosis in a Siamese cat with $\beta$-galactosidase deficiency. Science 174: 838-839.

Beaudet, A. L. (1983) Disorders of glycoprotein degradation: Mannosidosis, fucosidosis, sialidosis, and aspartylglycosaminoria. In The Metabolic Basis of Inherited Disease, J. B. Stanbury, J. B. Wyngaarden, D. S. Fredrickson, J. L. Goldstein, and M. S. Brown, eds., pp. 778-802, McGraw-Hill, New York.

Blakemore, W. F. (1986) A case of mannosidosis in the cat: Clinical and histopathological findings. J. Small Anim. Pract. 27: 447-455.

Braak, E., H. Braak, H. Strenge, and U. Muhtaroglu (1980) Age-related alterations of the proximal axon segment in lamina IIIab-pyramidal cells of the human isocortex: A Golgi and fine structural study. J. Hirnforsch. 21: 531-535.

Constantopoulos, G., K. Iqbal, and A. S. Dekaban (1980) Mucopolysaccharidosis types $1 \mathrm{H}$, IS, II, and IIIA: Glycosaminoglycans and lipids of isolated brain cells and other fractions from autopsied tissues. J. Neurochem. 34: 1399-1411.

Cork, L., J. F. Munnell, M. D. Lorenz, J. V. Murphy, H. J. Baker, and M. C. Rattazzi (1977) GM2 ganglioside lysosomal storage disease in cats with $\beta$-hexosaminidase deficiency. Science 196: 1014-1017.

Desnick, R. J., S. R. Thorpe, and M. B. Fiddler (1976) Toward enzyme therapy for lysosomal storage diseases. Physiol. Rev. 56: 5-99.

Dorling, P. R., C. R. Huxtable, and P. Vogel (1978) Lysosomal storage in Swainsona spp. toxicosis: An induced mannosidosis. Neuropathol. Appl. Ncurobiol. 4: 285-295.

Dorling, P. R., C. R. Huxtable, and S. M. Colegate (1980) Inhibition of lysosomal $\alpha$-mannosidase by swainsonine, an indolizadine alkaloid isolated from Swainsona canescens. Biochem. J. 191: 649-651.

Fairén, A., A. Peters, and J. Saldanha (1977) A new procedure for examining Golgi impregnated neurons by light and electron microscopy. J. Neurocytol. 6: 311-337.

Hartley, W. J. (1971) Some observations on the pathology of Swainsona spp. poisoning in farm livestock in eastern Australia. Acta Neuropathol. 18: 342-355.

Jellinger, K. (1973) Neuroaxonal dystrophy: Its natural history and related disorders. In Progress in Neuropathology, vol. 2, H. M. Zimmerman, ed., pp. 129-180, Grune and Stratton, New York.

Jolly, R. D. (1971) The pathology of the central nervous system in pseudolipidosis of Angus calves. J. Pathol. 103: 113-121.

Ledeen, R. W. (1984) Biology of gangliosides: Neuritogenic and neuronotrophic properties. J. Neurosci. Res. 12: 147-159.

Lovell, K. L., and M. Z. Jones (1985) Axonal and myelin lesions in $\alpha$-mannosidosis: Ultrastructural characteristics. Acta Neuropathol. 65: 293-299.

Mitani, A., M. Shimokouchi, K. Itoh, S. Nomura, M. Kudo, and N. Mizuno (1985) Morphology and laminar organization of electrophysiologically identified neurons in the primary auditory cortex in the cat. J. Comp. Neurol. 235: 430-447.

Molyneux, R. J., and L. F. James (1982) Loco intoxication: Indolizadine alkaloids of spotted locoweed (Astragalus lentiginosus). Science 216: 190-191

Novikoff, P. M., D. Touster, A. B. Novikoff, and D. P. Tulsiani (1985) Effects of swainsonine on rat liver and kidney: Biochemical and morphological studies. J. Cell Biol. 101: 339-349.

Purpura, D. P. (1979) Pathobiology of cortical neurons in metabolic and unclassified amentias. In Congenital and Acquired Cognitive Disorders, R. Katzman, ed., pp. 43-48, Raven, New York.

Purpura, D. P., and H. J. Baker (1978) Meganeurite and other aberrant processes of neurons in feline GM1 gangliosidosis. Brain Res. 143: 13-26.
Purpura, D. P., and K. Suzuki (1976) Distortion of neuronal geometry and formation of aberrant synapses in neuronal storage disease. Brain Res. 116: 1-21.

Purpura, D. P., and S. U. Walkley (1981) Aberrant neurite and spine generation in mature neurons in the gangliosidoses. In Gangliosidose. in Neurological and Neuromuscular Function, Development, and Repair, M. M. Rapport and A. Gorio, eds., pp. 1-16, Raven, New York.

Purpura, D. P., G. D. Pappas, and H. J. Baker (1978) Fine structure of meganeurites and secondary neurite growth processes in feline GM1 gangliosidosis. Brain Res. 143: 1-12.

Roisen, F. J., H. Bartfeld, R. Nagele, and G. Yorke (1981) Ganglioside stimulation of axonal sprouting in vitro. Science 214: 577-578.

Rybak, S., I. Ginzburg, and E. Yavin (1983) Gangliosides stimulate neurite outgrowth and induce tubulin mRNA accumulation in neural cells. Biochem. Biophys. Res. Commun. 116: 974-980.

Siegel, D. A., S. U. Walkley, and K. Suzuki (1982) Characterization of a specific $\alpha$-mannosidase inhibitor from "locoweed" (Astragalus lentiginosus). Science 216: 190-191.

Suzuki, K. (1976) Neuronal storage disease: A review. In Progress in Neuropathology, vol. 3, H. M. Zimmerman, ed., pp. 173-202, Grune and Stratton, New York.

Terry, R. D., and M. Weiss (1963) Studies in Tay-Sachs disease II Ultrastructure of cerebrum. J. Neuropathol. Exp. Neurol. 22: 18-55.

Tulsiani, D. R. P., and O. Touster (1983) Swainsonine, a potent mannosidase inhibitor, elevates rat liver and brain lysosomal $\alpha$-v-mannosidase, decreases Golgi $\alpha$-D-mannosidase II, and increases the plasma levels of several acid hydrolases. Arch. Biochem. Biophys. 224. 594-600.

Vandevelde, M., R. Fankhauser, P. Bichsel, U. Wiesmann, and N. Herschkowitz (1982) Hereditary neurovisceral mannosidosis associated with $\alpha$-mannosidase deficiency in a family of Persian cats. Acta Neuropathol. 58: 64-68.

Walkley, S. U. (1987a) Further studies on ectopic dendrite growth and other geometrical distortions of neurons in feline GM1 gangliosidosis. Neuroscience 21: 313-331.

Walkley, S. U. (1987b) Pathobiology of neuronal storage disease. Int. Rev. Neurobiol. 29: 191-244.

Walkley, S. U., and H. J. Baker (1984) Sphingomyelin lipidosis in a cat. II. Golgi studies. Acta Neuropathol. 65: 138-144.

Walkley, S. U., and M. E. Haskins (1982) Aberrant neurite and meganeurite development in a feline model of mucopolysaccharidosis (MPS) type 1 as revealed by the Golgi method. Soc. Neurosci. Abstr. 8: 1009.

Walkley, S. U., and L. F. James (1984) Locoweed-induced neuronal storage disease characterized by meganeurite formation. Brain Res. 324: $145-150$.

Walkley, S. U., and A. L. Pierok (1986) Ferric ion-ferrocyanide staining in ganglioside storage disease establishes that meganeurites are of axon hillock origin and distinct from axonal spheroids. Brain Res. 382: 379-386.

Walkley, S. U., and D. A. Siegel (1985) Ectopic dendritogenesis occurs on cortical pyramidal neurons in swainsonine-induced feline $\alpha$-mannosidosis. Dev. Brain Res. 20: 143-148.

Walkley, S. U., II. J. Baker, and D. P. Purpura (1980) Morphological changes in feline GMl gangliosidosis: A Golgi study. In Animal Models of Neurological Disease, F. C. Rose and P. O. Behan, eds., pp. 419429, Pitmans, London.

Walkley, S. U., W. F. Blakemore, and D. P. Purpura (1981a) Alterations in neuron morphology in feline mannosidosis: A Golgi study. Acta Neuropathol. 53: 75-79.

Walkley, S. U., S. Wurzelmann, and D. P. Purpura (1981b) Ultrastructure of neurites and meganeurites of cortical pyramidal neurons in feline gangliosidosis as revealed by the combined Golgi-EM technique. Brain Res. 211: 393-398.

Walkley, S. U., S. Wurzelmann, and D. A. Siegel (1985) Combined Golgi-EM study of cortical pyramidal neurons with ectopic neurites in swainsonine-induced feline $\alpha$-mannosidosis. J. Neuropathol. Exp. Neurol. 44: 352.

Walkley, S. U., S. Wurzelmann, and D. A. Siegel (1986) Ultrastructural changes in cerebral cortical neurons in swainsonine-induced and inherited feline $\alpha$-mannosidosis. J. Cell Biol. 103: 76a.

Walkley, S. U., S. Wurzelmann, and D. A. Siegel (1987) Ectopic axon hillock-associated neurite growth is maintained in metabolically reversed swainsonine-induced neuronal storage disease. Brain Res. 410: 89-96. 
Wenger, D. A., M. Sattler, T. Kudoh, S. P. Snyder, and R. S. Kingston (1980) Niemann-Pick disease: A genetic model in Siamese cats. Science 208: 1471-1473.

Williams, R. S., I. T. Gott, R. J. Ferrante, and V. S. Caviness (1977) The cellular pathology of neuronal ceroid lipofuscinosis. Arch. Neurol. 34: 278-305.
Winer, J. A. (1984) The pyramidal neurons in layer III of cat primary auditory cortex (AI). J. Comp. Neurol. 229: 476-496.

Wood, P. A., M. R. McBride, H. J. Baker, and S. T. Christian (1985) Fluorescence polarization analysis, lipid composition, and $\mathrm{Na}^{+}, \mathrm{K}^{+}$ ATPase kinetics of synaptosomal membranes in feline GMl and GM2 gangliosidosis. J.' Neurochem. 44: 947-956. 